\title{
Perancangan Desain Motif Baju sebagai Penunjang Identitas Tradisi Malam Selawe di Gresik
}

\author{
Nur Adilah Luthfiyyatur Rohmah, Putri Dwitasari, dan Didit Prasetyo \\ Departemen Desain Komunikasi Visual, Fakultas Desain Kreatif dan Bisnis Digital, \\ Institut Teknologi Sepuluh Nopember, Surabaya, Indonesia \\ e-mail:nuradilahlr@gmail.com
}

\begin{abstract}
Abstrak-Tradisi Malam Selawe merupakan kegiatan mencari berkah yang rutin diadakan setiap tahun pada akhir bulan Ramadhan. Tetapi dari beberapa masyarakat, khususnya para remaja Gresik sendiri masih kurang memahami dan menyalahartikan makna dari tradisi itu diadakan. Sehingga dalam kegiatan Tradisi Malam Selawe membutuhkan media yang dapat digunakan sebagai media pengenalan sejarah dan budaya dalam bentuk merchandise berupa desain motif baju. Perancangan desain merchandise ini menggunakan beberapa metode yaitu, observasi, analisis segmentasi dan depth interview. Metode perancangannya dimulai dari tahap pengumpulan data, melakukan analisis data, selanjutnya membuat konsep visual desain melalui sketsa digital dengan membuat tiga desain motif yang saling berhubungan. Desain motif yang dibuat diadaptasi dari elemen-elemen yang ada dalam Tradisi Malam Selawe mencakup sejarah, makna, kebudayaan, dan aktifitas masyarakat sekitar untuk diwujudkan menjadi identitas visual Tradisi Malam Selawe. Tujuan perancangan ini adalah untuk membuat desain merchandise Tradisi Malam Selawe sebagai media pengenalan sejarah dan budaya bagi masyarakat yang mengikuti kegiatan.
\end{abstract}

Kata Kunci-desain motif, identitas, malam selawe, merchandise, tradisi

Abstract -Malam Selawe tradition is a blessing-seeking activity that is routinely held every year at the end of the month of Ramadan. However, some people, especially the Gresik teenagers themselves still do not understand and misinterpret the meaning of the tradition being held. So that in the Malam Selawe tradition, it requires media that can be used as a medium for introducing history and culture in the form of merchandise in the form of clothing motif designs. The design of this merchandise design uses several methods, namely, observation, segmentation analysis and depth interviews. The design method starts from the data collection stage, performs data analysis, then creates a visual design concept through digital sketches by making three interconnected motif designs. The motif designs that are made are adapted from elements that exist in the Malam Selawe tradition, including history, meaning, culture, and activities of the surrounding community to be transformed into a visual identity of the Selawe Night Tradition. The purpose of this design is to design Malam Selawe Tradition merchandise as a medium for introducing history and culture to the people who participate in the activity.

Keywords-motif designs, identity, malam selawe, merchandise, traditions

\section{PENDAHULUAN}

Kabupaten Gresik merupakan sebuah wilayah dari Jawa Timur yang berbatasan dengan Kota Surabaya dan Selat Madura di sebelah timur, Kabupaten Lamongan di sebelah barat, Laut Jawa di sebelah utara, serta Kabupaten Sidoarjo dan Mojokerto di sebelah selatan [1]. Selain dikenal sebagai Kota Industri dan Kota Santri, kota Gresik juga bisa disebut dengan Kota Wali, karena keberadaan dua tokoh Walisongo yang menyebarkan ajaran islam pada kota ini [2]. Kabupaten Gresik memiliki banyak objek wisata religi islam yang mengandung nilai sejarah perkembangan ajaran islam di pulau jawa dan banyak dikunjungi oleh wisatawan dari dalam maupun luar daerah. Salah satu objek wisata religi yang terkenal adalah Makam Sunan Giri yang berada di Desa Giri, Kecamatan Kebomas [3].

Tradisi ziarah makam memang mengalami suatu perkembangan yang penting ketika pariwisata masuk dalam tradisi. Pemerintah Gresik dan pihak swasta telah berkontribusi memperbaiki infrastruktur, terutama jalan raya untuk memberikan kemudahan akses jalan bagi para peziarah [4]. Banyaknya peziarah yang datang dari berbagai daerah tentu mendatangkan rezeki bagi masyarakat sekitar makam dan pasti dapat dihitung nilai ekonominya [5]. Makam Sunan Giri selalu ramai dengan datangnya pengunjung hingga puncaknya berada ketika menjelang hari akhir ramadhan. Umat Muslim mengenal satu malam istimewa pada bulan ramadhan yakni malam Lailatul Qadar. Konon, malam itu jatuh pada malam-malam ganjil dalam sepuluh hari terakhir bulan suci tersebut [6]. Kemudian Sunan Giri menciptakan tradisi Malam Selawe dimana dalam tradisi tersebut mulanya dimanfaatkan para santri untuk ber-I'tikaf di Masjid Giri tempat suci pusat mereka belajar [7]. Dalam tradisi tersebut para santri berharap mendapatkan berkah Malam Lailatul Qadar pada Malam Selawe sebelum mudik ke rumah masingmasing. Tradisi tersebut sudah berlangsung selama turuntemurun dan masih dilestarikan oleh masyarakat sekitar hingga sekarang [8]. Seperti juga dapat dilihat pada Gambar 1. 


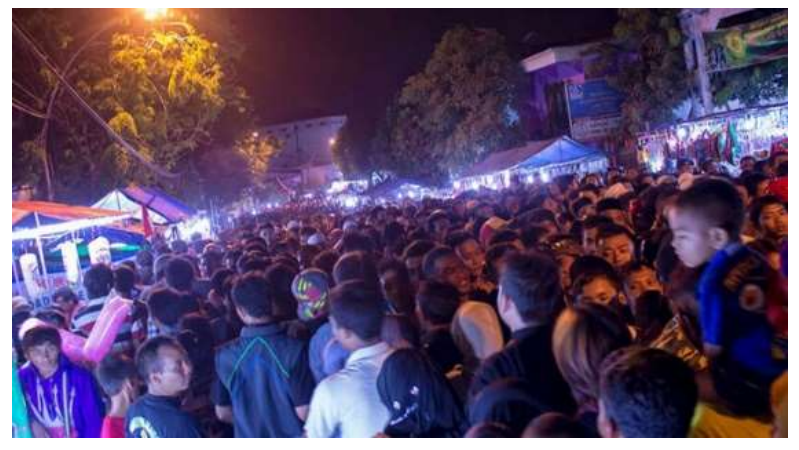

Gambar 1. Potret Malam Selawe, sebuah tradisi turun temurun di kota Gresik (Sumber: google.com).

Menurut Wakil Ketua Yayasan Makam Sunan Giri, Pak Sobirin mengatakan kegiatan yang biasanya dilakukan pada Malam Selawe selain I'tikaf dan ziarah ke makam adalah melaksanakan shalat tasbih, berdzikir, dan membaca AlQur'an di Masjid Jami Giri dengan tujuan untuk meningkatkan ketakwaan dan keimanan kepada Allah SWT. Masyarakat Gresik begitu mempercayai Tradisi Malam Selawe sebagai malam yang paling mulia hingga kesibukan masyarakat dalam menyiapkan pelaksanaan tradisi tersebut begitu ramai hingga mulai bermunculan para pedagang yang berjualan makanan khas daerah hingga souvenir untuk menarik minat pengunjung (Gambar 2). Makin tahun acara yang diadakan ketika Malam Selawe makin bervariasi dengan diadakannya kegiatan perlombaan dan Giri Expo untuk meramaikan acara. Hal ini membuat sebagian dari Masyarakat Gresik, khususnya para remaja masih banyak yang belum mengetahui makna yang sebenarnya dari diadakannya Tradisi Malam Selawe. Mereka mengganggap bahwa Tradisi Malam Selawe hanya berupa pasar malam dan acara perlombaan. Penyebab kejadian ini dikarenakan adanya perubahan-perubahan yang terjadi dalam Tradisi Malam Selawe membuat beberapa masyarakat menyalahartikan dan kurang memahami makna inti dan tujuan diadakannya kegiatan Tradisi Malam Selawe.

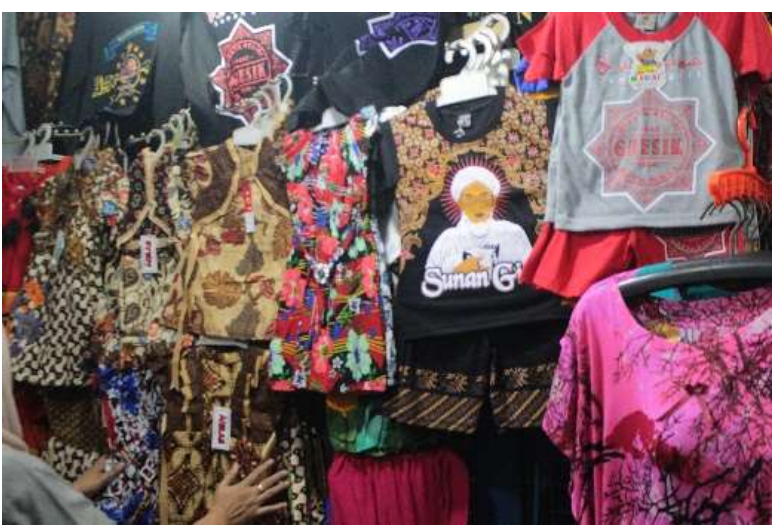

Gambar 2. Souvenir kaos pada Malam Selawe.

Oleh sebab itu, Tradisi Malam Selawe membutuhkan media sebagai sarana pembentuk identitas guna meluruskan pandangan masyarakat mengenai makna dan trend baru yang masih bisa dikorelasikan berupa media merchandise. Dengan menggunakan media merchandise dapat diyakini mudah untuk dilihat dan dimanfaatkan oleh wisatawan. Komunikasi visual merupakan salah satu cara penyampaian pesan secara visual melalui sesuatu yang dapat dilihat berupa, gambar, ilustrasi, serta tulisan dan jenis-jenis yang lainnya dengan prinsip selama pesan dapat dilihat [9]. Untuk itu desain merchandise ini dibuat dengan memfokuskan pada desain motif baju dengan menambahkan elemen sejarah, kebudayaan, makna, dan aktivitas masyarakat dari Tradisi Malam Selawe dimana dalam pembuatan desain motif baju ini akan dibuat tiga motif alternatif dengan masing-masing motif memiliki cerita dan filosofi tersendiri pada setiap desainnya.

Alasan memilih desain motif baju sebagai media merchandise yang digunakan karena target audiens yang dituju adalah kalangan dewasa muda dengan rentang usia 2328 tahun yang peduli akan fashion dan penampilan. Selain itu, pada lokasi kegiatan terdapat banyak penjual yang menjajahkan souvenir berupa pakaian tetapi Sebagian besar jenis desain dan motif yang cenderung mirip antara satu dan lainnya. Motif pakaian yang dijual di lokasi kegiatan pada umumnya menggambarkan ilustrasi portrait Sunan Giri, kaligrafi, tipografi Wisata Religi Makam Sunan Giri, motif batik daerah lain dan siluet Makam Sunan Giri. Sehingga perancangan ini dilakukan dengan harapan desain motif baju yang dirancang dapat menjadi referensi media pengenal sejarah dan makna budaya Tradisi Malam Selawe yang dapat diterima dan diminati wisatawan.

Berdasarkan latar belakang yang telah diuraikan sebelumnya, sehingga dapat diperoleh rumusan masalah: "Bagaimana merancang merchandise berupa desain motif baju sebagai media pengenalan Tradisi Malam Selawe di Kabupaten Gresik?"

Sesuai dengan rumusan masalah yang telah didapatkan sebelumnya, maka tujuan dari perancangan ini yaitu:

(1) Menciptakan merchandise untuk mengenalkan sejarah dan makna budaya Tradisi Malam Selawe;

(2) Menambah awareness wisatawan dengan desain motif baju yang khas dan unik;

(3) Menambah kesan bagi para wisatawan yang berkunjung pada kegiatan Tradisi Malam Selawe. Adapun batasan masalah yang disebutkan dalam perancangan ini agar fokus terhadap merchandise yang dibuat berupa motif baju serta tidak membahas mengenai merchandise lain yang tidak ada hubungannya dengan outfit pakaian.

Perancangan ini diharapkan dapat mengenalkan salah satu kebudayaan dari Kota Gresik yaitu Tradisi Malam Selawe kepada masyarakat dan wisatawan, serta mahasiswa selaku perancang mendapatkan pengetahuan baru tentang bagaimana merancang sebuah merchandise dalam bentuk desain motif baju dengan output berupa kemeja, dan menyalurkan wawasan yang didapakan dari hasil observasi.

\section{METODE PENELITIAN}

Dalam mendukung perancangan ini, diperlukan sejumlah data pendukung dan proses pengumpulan data ini dilakukan dengan cara melakukan; Pertama, Wawancara (depth interview) dengan Wakil Ketua Yayasan Makam Sunan Giri, pada tanggal 31 Oktober 2020 pukul 09:35 WIB. Wawancara 
difokuskan untuk mengumpulkan dan menggali data mengenai Sunan Giri mulai dari biografi kehidupan hingga peninggalan-peninggalan yang menjadi bukti keberadaan Sunan Giri khususnya Tradisi Malam Selawe dengan membuat pertanyaan berbentuk uraian dan menggunakan teknik semisruktur. Wawancara juga dilakukan kepada pengunjung yang pernah mengikuti kegiatan Tradisi Malam Selawe untuk mengetahui pemahaman mengenai tujuan diadakan kegiatan tersebut dan minat mereka dalam membeli merchandise. Wawancara ini dilakukan pada warga asli desa Giri dan luar daerah Giri.

Kedua, observasi dilakukan dimana dalam metode ini proses pengumpulan data dilakukan dengan melakukan pengamatan secara langsung pada lokasi Makam Sunan Giri dan melihat bukti-bukti peninggalan Sunan Giri. Dalam metode ini dokumentasi juga dilakukan dengan mengumpulkan foto-foto yang berhubungan dengan Tradisi Malam Selawe. Ketiga, metode analisis segmentasi dilakukan guna menentukan pemasaran merchandise yang akan dirancang sebagai berikut.

\section{Demografis}

Jenis Kelamin: Laki-laki dan perempuan

Usia: 23-28 tahun

Rentang usia ini dipilih berdasarkan hasil wawancara dan observasi yang dilakukan, selain itu karena pada usia 20 tahun adalah umur produktif untuk memahami dan menilai kebudayaan terutama tentang motif baju. Penghasilan: > Rp.3.000.000

2. Geografis

Target audiens dari perancangan ini yakni warga Indonesia, khususnya masyarakat yang tinggal di Kabupaten Gresik atau pernah mengikuti kegiatan Tradisi Malam Selawe.

3. Psikografis

Target audiens memiliki minat dan ketertarikan akan budaya dan sejarah daerah lokal, sering melakukan ziarah makam wali, peduli akan penampilan/fashion, berjiwa seni tinggi dan kreatif, mengikuti perkembangan teknologi.

Data tersebut selanjutnya melalui tahap analisis data menggunakan metode $5 \mathrm{~W}+1 \mathrm{H}$ dengan menjawab pertayaan apa, siapa, dimana, kapan, mengapa, dan bagaimana sebagai langkah untuk mengoptimalkan proses perancangan dan pertimbangan:

a. Apa permasalahan yang ditemukan?

b. Siapa target audiensnya?

c. Dimana lokasi perancangan ini dilakukan?

d. Kapan perancangan ini dilaksanakan?

e. Mengapa perancangan ini harus dibuat?

f. Bagaimana merancangnya?

\section{PEMBAHASAN}

\section{Konsep Visual}

Konsep visual dari perancangan desain motibaju ini ditentukan berdasarkan hasil dari depth interview, observasi, dan analisis segmentasi yang telah dilakukan. Big concept yang didapatkan dari perancangan ini adalah "a Unique way of Introducing the Culture of Malam Selawe" yang memiliki arti cara unik mengenalkan budaya Malam Selawe pada pengunjung yang mengikuti kegiatan dengan menampilkan unsur-unsur yang berkaitan dengan tradisi dibidang budaya, sejarah, makna, dan aktivitas masyarakat sebagai perpaduan yang menarik. Unsur dan elemen tersebut dipilih karena diharapkan dapat menarik perhatian audiens, karena umumnya para target audiens merchandise yang disasar memiliki minat dan tertarik akan budaya dan sejarah serta peduli akan penampilan.

Desain pada merchandise motif baju ini juga memiliki diferensiasi tema khusus pada tiap motif yang akan dirancang dengan memberi kesan unik, nyaman, dan fleksibel digunakan. Dengan dibuatkannya desain merchandise motif baju yang mencirikan identitas Tradisi Malam Selawe diharapkan nantinya dapat menjadi sarana referensi gaya visual yang berbeda serta meningkatkan awareness wisatawan yang mengikuti atau hanya sekedar berkunjung di Tradisi Malam Selawe [10].

\section{Kriteria Desain}

A. Gaya Gambar dan Warna

Pada perancangan desian motif baju sebagai merchandise Tradisi Malam Selawe ini fokus menerapkan aliran style illustrasi whimsical art. Gaya ini merupakan seni yang bersemangat, membuat bahagia dengan warna-warna cerah dan menyenangkan. Untuk warna pada bahan kain pakaian sendiri menggunakan warna netral yaitu warna putih agar desain pada pakaian dapat terlihat jelas.

\section{B. Tipografi}

Jenis typeface yang dipilih dalam perancangan ini adalah Upakarti. Font tersebut dipilih karena memberi kesan tradisional, unik, dan menampilkan citra dari budaya jawa sehingga terkesan cocok dengan style motif yang akan dirancang (Gambar 3).

\section{Abcdefghijklm nopqrstuvwxyz}

\section{0!@. 0}

\author{
Gambar 3. Upakarti Font \\ Sumber: Dokumentasi Pribadi
}

C. Komponen Motif

Kriteria yang digunakan dalam motif utama mencakup elemen yang dominan bersifat bebas. Sedangkan ornamen elemen tambahan bersifat mendukung motif utama bersifat sebagai background untuk mengisi ruang kosong pada bidang.

\section{Proses perancangan desain}

A. Sketsa Digital

Proses visualisasi desain diawali dengan membuat sketsa desain secara digital menggunakan software Adobe Photoshop. Dalam proses ini elemen motif dibuat dengan tampilan hitam putih dengan coretan yang menggunakan pencil brush sebagai pola desain motif yang akan dirancang. Berikut adalah hasil alternatif sketsa digital desain motif baju yang telah dibuat: 


\section{Sketsa Motif 1 (Gambar 4).}

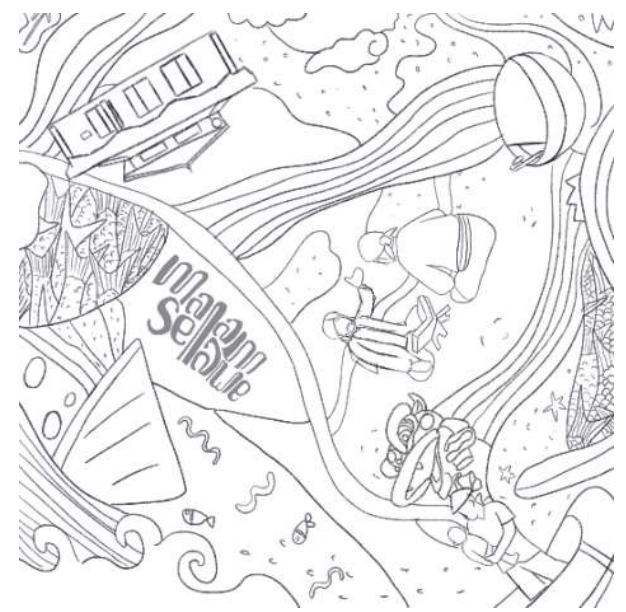

Gambar 4. Sketsa Motif Desain 1.

Sketsa Motif 2 (Gambar 5).

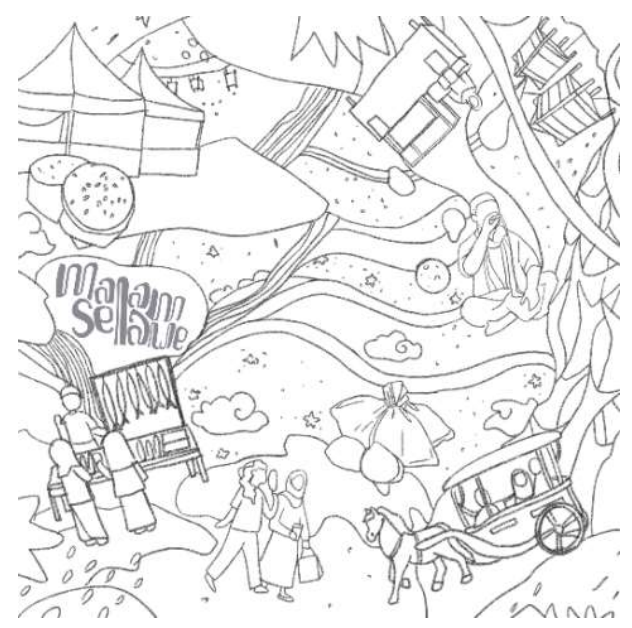

Gambar 5. Sketsa Motif Desain 2.

Sketsa Motif 3 (Gambar 6).

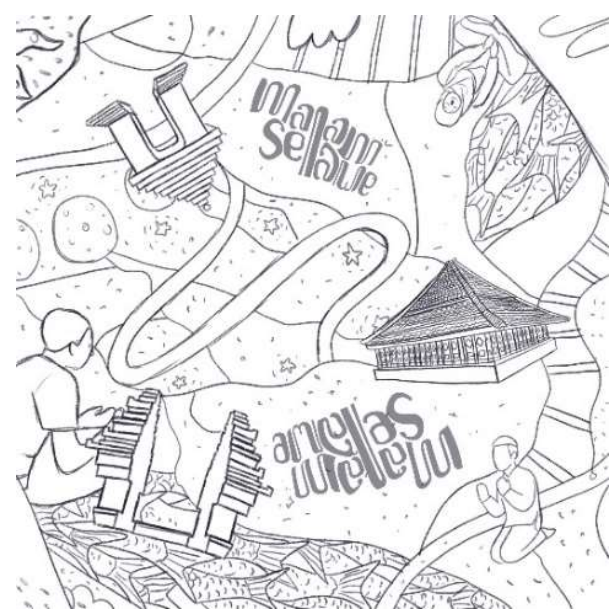

Gambar 6. Sketsa Motif Desain 3
B. Final Desain

Proses berikutnya adalah mengembangkan sketsa digital yang telah dibuat dengan melakukan proses pewarnaan secara digital untuk mendapatkan hasil final desain.

\section{Motif 1 (Gambar 7).}

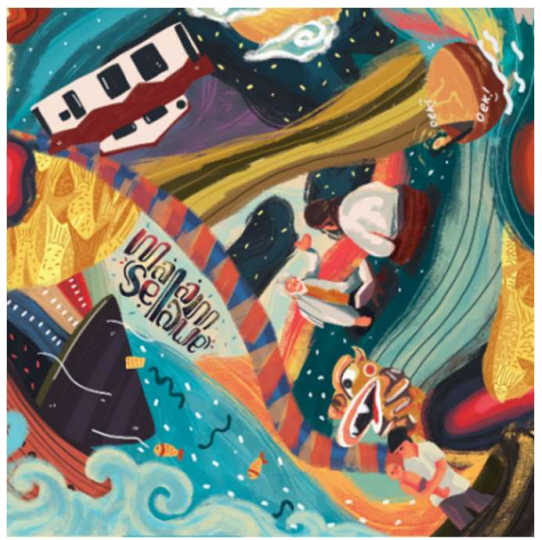

Gambar 7. Final Desain Motif 1 .

\section{Spesifikasi Desain}

Judul : Biographical History of Sunan Giri

Ukuran : 3000px x 3000px

Media : Digital print, Kain Toyobo NY

Sunan Giri merupakan tokoh utama dalam Tradisi Malam Selawe, dalam desain motif 1 menggambarkan sejarah dari dibuangnya Raden Paku ke laut kemudian ditemukan oleh seorang nelayan hingga ia mendirikan sebuah pesantren di daerah Giri [11]. Subjek utama dalam motif digambarkan Sunan Giri sedang berguru kepada Sunan Ampel yang masih ada hubungan keluarga dengannya. Background yang terdapat pada desain motif 1 didominasi oleh ombak dan batik bandeng untuk menonjolkan ciri khas Kota Gresik dengan warna biru sebagai warna dominan.

\section{Motif 2 (Gambar 8)}

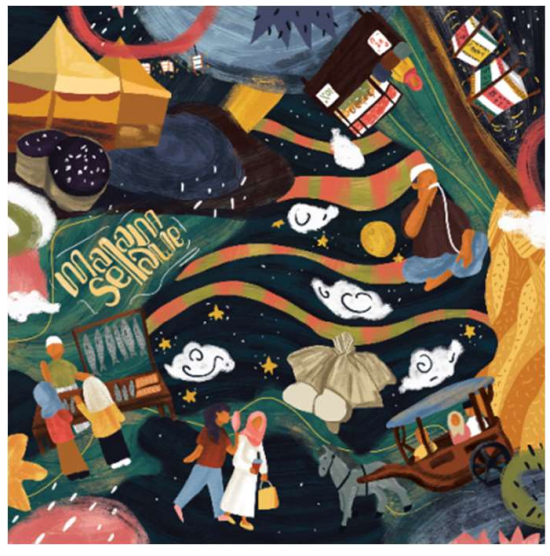

Gambar 8. Final Desain Motif 2.

\section{Spesifikasi Desain}

Judul : The Other Side of Malam Selawe

Ukuran : 3000px x 3000px

Media : Digital print, Kain Toyobo NY 
Sumber gagasan dari desain motif 2 berasal dari aktivitas masyarakat pada saat puncak Tradisi Malam Selawe diadakan. Aktivitas tersebut berupa kegiatan yang dilakukan seperti belanja di kios-kios, perlombaan yang diadakan pada acara Giri Expo, serta datangnya para wisatawan untuk menikmati nuansa tradisi yang disajikan. Background utama pada motif berwarna indigo kehitaman sebagai warna dominan untuk memberi kesan malam dengan penambahan unsur bulan dan bintang yang digambarkan sebagai malam Lailatul Qadar. Elemen lain seperti damar kurung, jajanan, batik bandeng juga ditampilkan sebagai penanda bahwa tradisi ini berasal dari Gresik.

\section{Motif 3 (Gambar 9)}

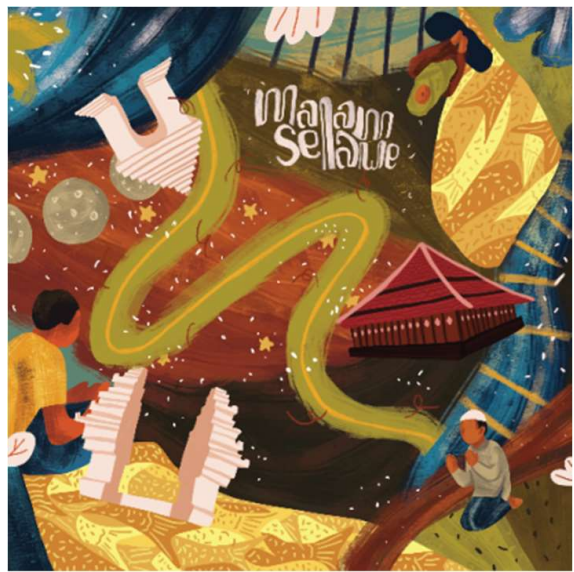

Gambar 9. Final Desain Motif 3

\section{Spesifikasi Desain}

Judul : Ngalap Berkah

Ukuran : 3000px x 3000px

Media : Digital print, Kain Toyobo NY

Subjek utama motif desain 3 yaitu makna dari Tradisi Malam Selawe diadakan. Gambar orang dengan tangan menengadah keatas menunjukkan orang tersebut sedang melakukan ibadah, seperti yang diketahui bahwa kegiatan ini diadakan memang untuk mencari berkah di malam yang istimewa. Unsur bangunan dari Makam Sunan Giri juga diambil sebagai pelengkap. Penggambaran background menggunakan warna hijau kecoklatan yang memberi nuansa alami dan sejuk pada lingkungan Giri. Seperti pada motif sebelumnya elemen objek disusun secara acak agar tidak terkesan kaku dan monoton.

\section{Sistem produksi Merchandise}

A. Media output

Berdasarkan hasil analisis segmentasi, dalam analisis tersebut didapatkan wisatawan rata-rata adalah seorang pekerja, peduli akan fashion dan cenderung mengikuti perkembangan teknologi. Sehingga media output yang dipilih dalam perancangan ini adalah outfit pakaian berupa dua jenis model kemeja. Produk tersebut dipilih karena kemeja terkesan formal, sopan, dan bisa digunakan pada kegiatan santai seperti berwisata.

B. Kriteria bahan

Kriteria bahan yang digunakan pada media cetak untuk desain merchandise adalah kain katun toyobo original import.
Kain tersebut dipilih karena jenis kain toyobo tidak kaku, ringan, adem, halus dan agak licin [12]. Kain katun toyobo memiliki ketebalan pas dengan serat kain yang tersusun rapat sehingga tidak menerawang, mudah menyerap keringat dan tidak membuat gerah. Sehingga katun toyobo cocok digunakan sebagai kemeja formal atau non-formal dan sebagai outer.

\section{Estimasi harga}

Produk kemeja dijual dengan harga yang dimulai dari Rp. $220.000,-$. Penentuan harga produk merchandise yang dibuat ini berdasarkan biaya pembuatan, jenis ukuran, bahan yang digunakan untuk satu kemeja dan model pakaian.

\section{Kemasan}

Kemasan merupakan salah satu faktor penting dalam penjualan, karena jika kemasan memiliki desain yang menarik dapat memberikan nilai jual dan mudah diingat oleh pembeli [13]. Kemasan digunakan sebagai

media pendukung pada perancangan untuk produk kemaja ini dengan menggunakan paperbag yang berbahan agak tebal dan didesain sesuai dengan motif baju yang akan dibeli. Paperbag dipilih karena ramah lingkungan dan terkesan simple tanpa menghilangkan kesan elegan.

\section{Implementasi desain}

Berikut adalah hasil dari implementasi visual desain motif baju pada layout kemeja yang dibuat dengan varian kemeja lengan pendek yang bisa digunakan untuk pria maupun wanita atau unisex, dan kemeja lengan panjang khusus wanita.

\section{A. Biographical History of Sunan Giri \\ Versi Unisex (Gambar 10).}

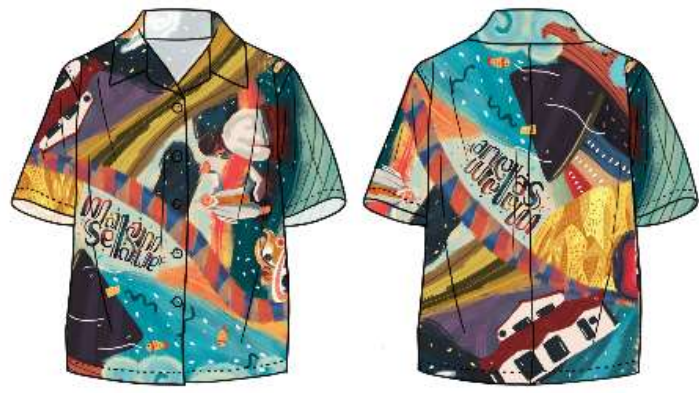

Gambar 10. Motif 1 versi Unisex.

Versi Kemeja Puffy (Gambar 11).
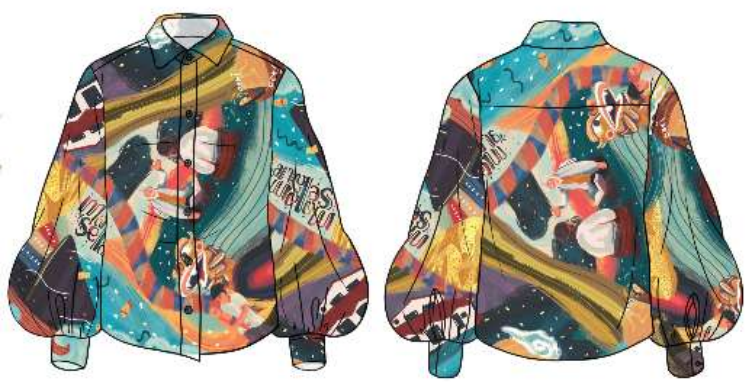

Gambar 11. Motif 1 versi Puffy Shirt 
B. The Other Side of Malam Selawe

Versi Unisex (Gambar 12).

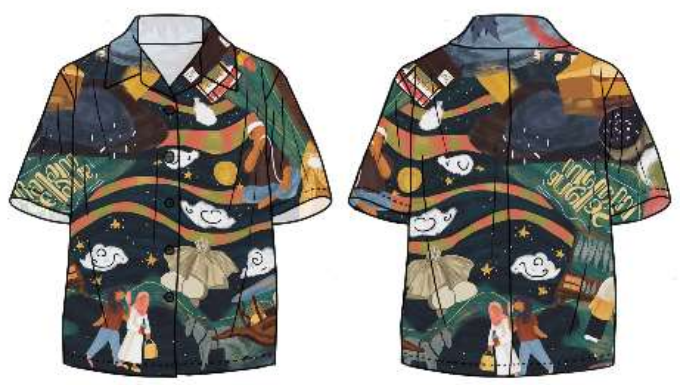

Gambar 12. Motif 2 versi Unisex

Versi Kemeja Puffy (Gambar 13)
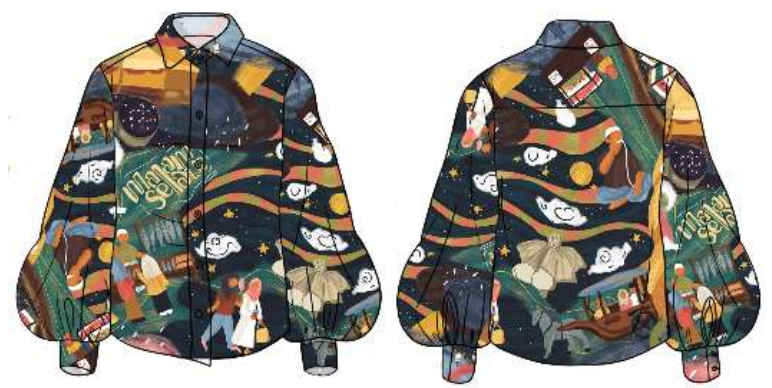

Gambar 13. Motif 2 versi Puffy Shirt

\section{Ngalap berkah}

Versi Unisex (Gambar 14).

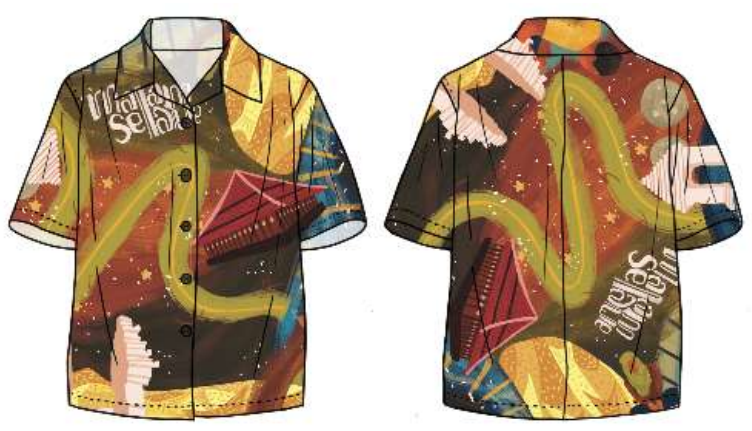

Gambar 14. Motif 3 versi Unisex.

Versi Kemeja Puffy (Gambar 15).
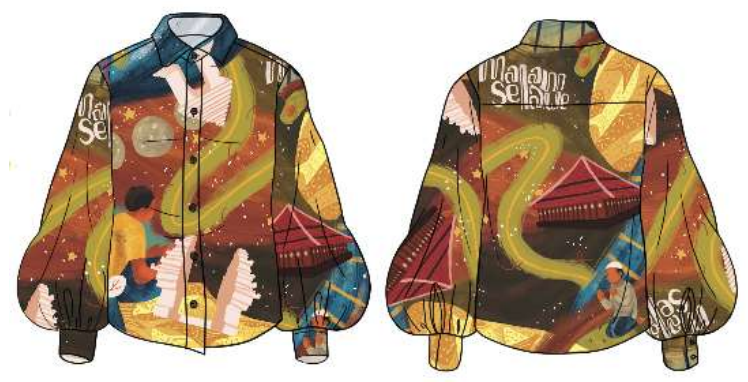

Gambar 15. Motif 3 versi Puffy Shirt.

\section{KESIMPULAN DAN SARAN}

\section{Kesimpulan}

Berdasarkan perancangan yang telah dilakukan dapat diambil kesimpulan bahwa desain merchandise motif baju dengan tema Tradisi Malam Selawe ditujukan sebagai sarana pembentuk identitas dengan mengenalkan tradisi khas Kabupaten Gresik ke masyarakat sekitar dan luar Gresik untuk meningkatkan awareness dan menarik perhatian bagi yang melihat maupun yang menggunakannya karena menimbulkan kesan bangga terhadap karya lokal khususnya generasi muda. Hasil dari desain motif baju menghasilkan beberapa motif diantaranya motif Biographical History of Sunan Giri, The Other Side of Malam Selawe, dan Ngalap Berkah. Perwujudan desain dari masing-masing motif yang dibuat tidak lepas dari unsur-unsur kebudayaan itu sendiri. Makna desain motif dapat dilihat dari penamaan motif. Bahan media cetak yang dipakai disesuaikan dengan daerah tropis sehingga kemeja akan nyaman dikenakan.

\section{Saran}

Dalam tahapan user testing yang telah dilakukan terdapat beberapa saran setelah melalui tahap produksi protoype diantaranya agar lebih memperhatikan pemilihan objek yang dijadikan elemen motif, dan diperlukan desain yang lebih sederhana serta membuat motifnya menjadi lebih kecil. Untuk warna dan ilustrasi unik dan jarang berbeda dengan mecrchandise lain yang ada di kawasan Makam Sunan Giri. Perlunya juga penambahan merchandise dengan variasi lain seperti masker, topi, maupun outer agar terdapat opsi lain sebagai bahan merchandise wisatawan.

\section{DAFTAR PUSTAKA}

[1] Amin, M.Q. (2020). Perancangan Destination Branding Wisata Religi Desa Bungah Kecamatan Bungah Kabupaten Gresik (Doctoral dissertation, Intitut Seni Indonesia Yogyakarta).

[2] Wati, R.P.R. (2019). Promosi Wisata Religi (Studi Deskriptif Tentang Upaya Promosi Wisata Religi Makam Siti Fatimah Binti Maimun Oleh Dinas Pariwisata dan Kebudayaan Kabupaten Gresik) (Doctoral dissertation, Universitas Airlangga)

[3] Santosa, B., Antariksa, A., \& Wulandari, L. D. (2014). Dinamika Ruang Wisata Religi Makam Sunan Giri Di Kabupaten Gresik. EL HARAKAH Jurnal Budaya Islam, 16(2), 174-202.

[4] Chambert-Loir, Henri dan Claude Guillot, Ziarah dan Wali di Dunia Islam, Jakarta: Serambi Ilmu,2007.

[5] Elmaningtias, P. (2017). Kontribusi Wisata Religi Sunan Giri Terhadap Kesejahteraan Masyarakat Gresik Tahun 20092015. Avatara, 5(3).

[6] Nor Hasanah, I. Beribadah Pada Malam Lailatul Qadr Beribadah Pada Malam Lailatul Qadr. Retrieved 10 December 2020, from $<$ https://www.scribd.com/doc/152641050/Beribadah-Pada-MalamLailatul-Qadr>

[7] Rahmawati, P. (2018) Malam Selawe Tradisi Ramadhan Warga Gresik Dan Pergeseran Maknanya. $<$ https://www.inibaru.id/tradisinesia/malam-selawe-tradisi-wargagresik-di-bulan-ramadan-dan-pergeseran-maknanya-lp>

[8] GILANG, W. L. (2011). PERANCANGAN VISUAL BUKU WISATA RELIGI ISLAM GRESIK (Doctoral dissertation, UPN" veteran" Jawa Timur).

[9] Tama, A. K. W., Novena, M. D., \& Lestari, S. Perancangan Merchandise Guna Menunjang Efektivitas Promosi. Journal Sensi, 3(1), 92-104.

[10] Christian, J. A., Bangsa, P. G., \& Malkisedek, M. H. (2018). Perancangan media komunikasi visual destination branding kampung lawas maspati Kota Surabaya. Jurnal DKV Adiwarna, 1(12), 11.

[11] NUR HAKIKI, R. A. H. M. A., \& DWIYANTI, S. (2020). Upaya Menarik Minat Wisatawan Religi terhadap Tata Rias Pengantin Giri Sekar Kedaton Gresik. Jurnal Tata Rias, 9(2). 
Nur Adilah Luthfiyyatur Rohmah, Putri Dwitasari, dan Didit Prasetyo

Perancangan Desain Motif Baju Sebagai Penunjang Identitas Tradisi Malam Selawe di Gresik

[12] Mizutex.com. 2017. Kain Katun Ima Polos Seperti Apa? Baca Penjelasan Ini Agar Tau Rahasianya. $<$ https://www.mizutex.com/mengenal-bahan-katun-ima-berkualitasdan-seperti-apa-ciri-cirinya/>
[13] Fitrimaghfira, B. N., \& Rizkiantono, R. E. (2019). Perancangan Clothing dengan Desain Khas Lombok sebagai Suvenir. Jurnal Sains dan Seni ITS, 8(1), 118-123. 